\title{
Steroid-responsive nephrotic syndrome and allergy: clinical studies
}

\author{
S R MEADOW AND J K SARSFIELD \\ Department of Paediatrics and Child Health, University of Leeds and St James's University Hospital, Leeds
}

MMARY Eighty-four children with steroid-responsive nephrotic syndrome who had been shown to have, or were believed to have, minimal change histology were investigated to study the relationship between steroid-responsive nephrotic syndrome and allergy. They were found to have a greater incidence of the standard atopic disorders-asthma, eczema, recurrent urticaria, and hay fever. Their 1st-degree relatives had an increased incidence of these atopic disorders too. A nasal discharge was a frequent precursor or an accompaniment of nephrotic syndrome, but an overt atopic disorder at the same time was rare. Such disorders, related to relapse, occurred in only 5 children; in none was it a consistent or recurrent happening at the time of each relapse. No example of pollen hypersensitivity nephrotic syndrome was found, and no particular allergen could be identified with certainty as responsible for a child's nephrotic syndrome. No association was found between the time of relapse and the season of the year, or the season in which the child was born. Children with nephrotic syndrome had a greater incidence of positive skin tests to common antigens, the comparative frequency of positive reactions to different antigens being similar to that found in children with asthma, although the total frequency was about half that of children with asthma. Despite the increased incidence of clinical features of atopy, measures to reduce the frequency of relapse of nephrotic syndrome by allergen avoidance, the use of disodium cromoglycate, and the use of a new oral antiallergic drug were unsuccessful.

Children with steroid-responsive nephrotic syndrome form a well-defined group. The renal biopsy shows a nearly normal appearance on light microscopical examination (minimal changes), and the syndrome responds to treatment with corticosteroid drugs; subsequent relapse is usual. This type of nephrotic syndrome is more common in early childhood than at any other time in life. The origin and cause remain a mystery, and effective management is limited.

There have been isolated case reports of the syndrome occurring in response to exposure to grass pollens. There have also been reports of the syndrome occurring at the same time as other allergic symptoms in atopic persons. ${ }^{1-4}$

The aim of this study was to define the relationship between steroid-responsive nephrotic syndrome of childhood and allergy. Eighty-four children with nephrotic syndrome form the basis of the study. Clinical and laboratory evidence of atopy in the children and their relatives are presented.

Management trials were designed to see if interruption of an allergic cause or mechanism could prevent relapse or reduce the need for corticosteroids.

\section{Methods}

Children. Three groups were studied.

\section{Nephrotic syndrome}

Sixty-two boys and 22 girls had nephrotic syndrome (heavy proteinuria $>0.05 \mathrm{~g} / \mathrm{kg}$ per day, serum albumin $<25 \mathrm{~g} / 1$, and variable oedema). The diagnosis of steroid-responsive nephrotic syndrome was made on the basis of a characteristic clinical history, confirmatory laboratory evidence, response to treatment with corticosteroids, and the absence of contradictory features (for example hypocomplementaemia, hypertension, persistent azotaemia, or haematuria). In 41 the renal biopsy showed 'minimal changes'. (It is unlikely that the $\mathbf{4 3}$ children who did not have biopsies would have shown histological appearances other than minimal changes because their clinical course and findings were even more typical of minimal change nephrotic syndrome than the 41 in whom the renal biopsy showed minimal changes only.)

Children with equivocal renal histology and other 
forms of nephrotic syndrome were excluded from the study. Two-thirds of the children had been referred by paediatricians outside Leeds. They had been referred because of problems with their management, and therefore many of them had had frequent relapses or needed unacceptably large doses of corticosteroids to stay in remission. It was not possible to include all 84 in each study, therefore the number of children included in each study was generally smaller than the total number of 84 . Unless otherwise stated, the children were not specifically selected for each study, and the different groups of 70 or so children reported were found to be comparable in terms of age, sex, pattern of illness, and amount of previous treatment.

Twelve had each had a single bout of nephrotic syndrome with no recurrence in the first 2 years after onset (single nephrotic syndrome). Seventy-two had had subsequent relapses, and most of these relapses had been frequent (relapsing nephrotic syndrome). Age at onset of nephrotic syndrome ranged from $1 \cdot 2$ to $13 \cdot 1$ (mean $5 \cdot 4$ ) years.

\section{Control group $A$}

This group comprised 80 children from a general paediatric outpatient clinic. Most had urine infections, respiratory tract infections, haematuria, or pains of unknown causes. Children whose prime complaint was asthma, eczema, or hay fever were excluded (although an atopic child presenting for another reason might be included). The children were chosen because they were about the same age and of the same sex as the children with nephrotic syndrome. Necessary limitation in the performance of certain tests resulted in further selection. Blood samples were obtained only if venepuncture was otherwise necessary for the child. Skin tests were done only after informed parental consent had been given, and if we thought the procedure would not upset the child.

\section{Control group $B$}

This group comprised 60 healthy children from a village near Leeds. The children were chosen to provide an approximate sex and age match to the children with nephrotic syndrome.

The study was approved by the hospital ethical committee.

Clinical studies. The history was taken at a series of specially arranged clinics. At the time of the visit all the children had been in remission for at least 2 weeks, and most of them had been in remission for many months.

A questionnaire about allergy in the child and family was completed separately by the two of us. We saw the parents separately, some parents seeing SRM first, others JKS. The information was recorded separately, but at the end of each session this information was compared to provide an agreed allergy status sheet for each patient. We did this to avoid bias in the collection and interpretation of possible allergy but in practice there was agreement between us on nearly all the children.

The following allergic illnesses were sought by direct questioning: asthma (recurrent wheezing), eczema (infantile or flexural), allergic rhinitis (hay fever), urticaria recurring at least twice, or occurring twice in response to a known provoking agent. At the start of the study questions were asked also about food allergy.

A history of the same disorders was sought in the child's siblings and parents (that is the 1st-degree relatives). The parents of the nephrotic children were asked to think back carefully to the time of onset or relapse of nephrotic syndrome to identify any preceding or accompanying incidents. Particular attention was paid to the time of year, associated symptoms, treatments, activities, diet, and domicile at the time of onset or relapse of the nephrotic syndrome. Each child had a physical examination and his urine was examined.

Clinical observations were compared using $\chi^{2}$ analysis.

Skin testing. Skin prick tests ${ }^{5}$ were performed on the ventral surface of the forearm using disposable No 25 gauge hypodermic needles. All patients were tested against solutions of house-dust, house-dust mite (Dermatophagoides pteronyssinus), grass pollen mix, mould mix, milk, egg, fish, and cereal. If the child had regular contact with a pet at home or at school, skin tests were performed with the relevant extract-for example cat fur or dog hair. Any child with a suspicious history for any food or allergen was tested against that allergen if available. Bencard allergen extracts were used.

Eosinophil count. The blood was placed in a sequestrene bottle and subsequently stained with $2 \%$ eosin in aqueous acetone. The eosinophils were counted in a Fuchs-Rosenthal counting chamber.

\section{Results}

History of allergic disorder. A positive history of an allergic disorder was present in $26(34 \%)$ of 77 children with nephrotic syndrome. A positive history was present in $6(55 \%)$ of 11 children with a single nephrotic syndrome, and in $20(31 \%)$ of 65 children with relapsing nephrotic syndrome. The 
disorders noted were: asthma (in 12), eczema (in 9), recurrent urticaria (in 8), and hay fever (in 4); 4 children had at least 2 of these disorders.

Evidence of food allergy was weak, and no clear case of food allergy was apparent.

The incidence of the 4 main allergic disorders in the control groups was significantly lower (Table 1).

Family history of allergic disorder. A history of at least one of the 4 main allergic disorders was present in at least one 1st-degree relative of 37 of the 75 children for whom parents could provide reliable details. The proportion was similar for children with relapsing or single nephrotic syndrome. It was a significantly higher proportion than the incidence of allergic disorders in the 1st-degree relatives of the control group B (Table 2).

\section{Search for seasonal or other provocative factors.}

\section{Upper respiratory tract infection}

The only fact consistently given by many parents was that onset of the syndrome and of the relapse had followed a 'cold' or, less often, a 'cough' and 'sore throat'. Thirty-five of 71 children with relapsing nephrotic syndrome had a history of at least 2 episodes of the syndrome within 3 days of such upper respiratory tract symptoms. In about half of these 35 children the relapses 'always' were associated with a 'cold'. Although the parents reported upper respiratory tract symptoms, there is no certainty that such respiratory symptoms were the result of infection and not due to allergic, physical, or emotional factors. However, in some cases other members of the family had had similar symptoms which suggested a communicable viral cause.

Table 1 Incidence of allergy (asthma, eczema, urticaria, or hay fever)

\begin{tabular}{llll}
\hline Group & \multicolumn{2}{l}{ Allergy } & $P$ \\
\cline { 2 - 3 } & No & \multicolumn{1}{l}{$P$} \\
\hline Nephrotic syndrome $(\mathrm{n}=77)$ & 26 & 34 & \\
Controls A $(\mathrm{n}=80)$ & 15 & 19 & $<0.01$ \\
Controls B $(\mathrm{n}=45)$ & 6 & 13 & $<0.01$ \\
\hline
\end{tabular}

Table 2 Incidence of asthma, eczema, urticaria, or hay fever in the 1st-degree relatives

\begin{tabular}{llll}
\hline Group & \multicolumn{2}{l}{$\begin{array}{l}\text { Affected 1st-degree } \\
\text { relative }\end{array}$} & $P$ \\
\cline { 2 - 3 } & No & $\%$ & \\
\hline Nephrotic children $(\mathrm{n}=75)$ & 37 & 50 & \\
Control A $(\mathrm{n}=79)$ & 29 & 37 & $<0.2$ \\
Control B $(\mathrm{n}=44)$ & 14 & 32 & $<0.01$ \\
\hline
\end{tabular}

Of the 12 children who had only a single bout of nephrotic syndrome there was associated 'cold' in only 3 , but the parents of 2 others remembered that acute wheezing had been the main preceding complaint (see below).

\section{Allergic disorder in relation to onset}

Three of 12 children who had each had a single nephrotic syndrome had had an allergic disorder in the 3 days preceding onset of oedema (asthma in 2, and eczema in 1). Two of 72 children with relapsing nephrotic syndrome had each had an allergic disorder (urticaria) within 3 days of onset of oedema.

\section{Seasonal factors}

Despite careful questioning and research none of 72 children with relapsing nephrotic syndrome could show a pattern of seasonal relapse followed by remission until the same season the following year.

The month of first onset is shown in Fig. 1 for children with either relapsing or single nephrotic syndrome. The onset was distributed throughout the year, being in the 6 winter months (October to March) for 38 children with relapsing nephrotic syndrome, and in the 6 summer months for the other 30 children with relapsing nephrotic syndrome. Onset was less common in April, May, and June.

To test the hypothesis that exposure to particular allergens in infancy, before maturation of the immunological process, was relevant, the month of birth of each child was noted. Of the 72 children with relapsing nephrotic syndrome the birth months were equally divided between the 6 winter months and the 6 summer ones, with a peak in July (Fig. 2). Although 6 of the children born in July had their onsets of nephrotic syndrome in the peak month of September, no consistent relationship could be found between the month of birth, month of onset of nephrotic syndrome, the pattern of the illness, or the associated or preceding illnesses.

\section{Children with hay fever}

Of the 4 children with a clear history of hay fever in none had the initial onset of nephrotic syndrome been at the time of hay fever, nor, indeed, had it been in the summer. One had had a recurrence (that is a relapse) at the time of hay fever symptoms. She presented with nephrotic syndrome in January, went into remission, and had no further trouble until 17 months later after she had spent an afternoon walking through hay fields. She developed severe allergic rhinitis that afternoon and within 3 days had generalised oedema of nephrotic syndrome. After this experience she avoided grass fields as much as possible. She had no further relapses in the hay fever season. 

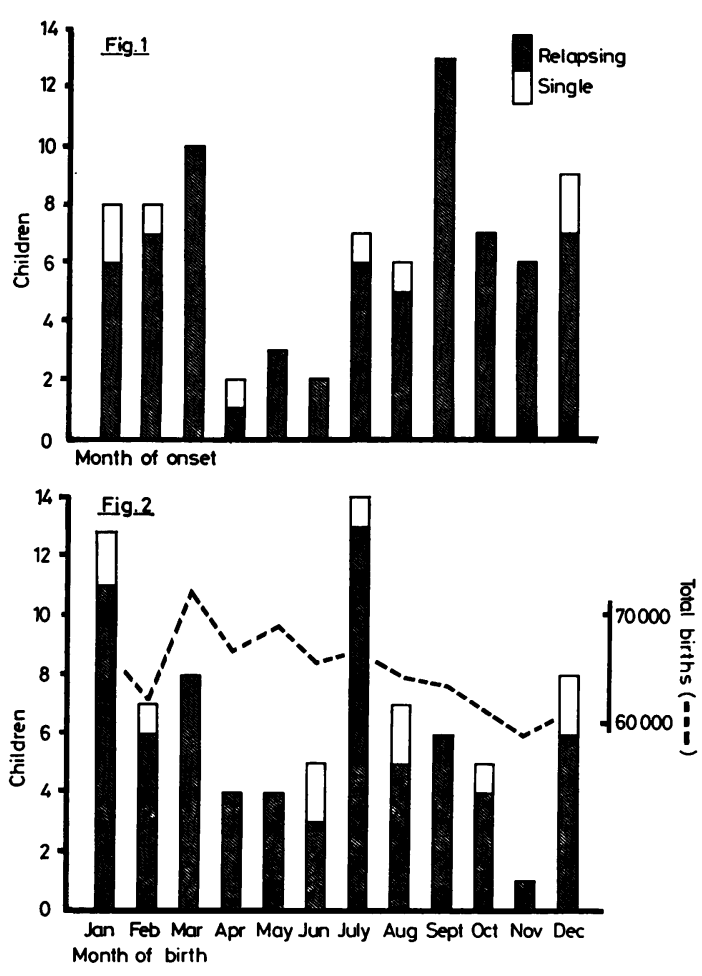

Fig. 1 Month of first onset of nephrotic syndrome. Single means that the child had no subsequent relapse.

Fig. 2 Month of birth of children with nephrotic syndrome. Dotted line shows the national distribution of births during the period that most of the children were born.

\section{Skin prick tests}

The response to skin prick tests was graded according to the number of positive reactions obtained. A weal of at least $2 \mathrm{~mm}$ diameter was considered positive. The following grades were used: grade $A=1$ positive test, grade $B=2-4$ positive tests, and grade $\mathbf{C}=$ at least 5 positive tests.

For each grade there was a higher proportion of nephrotic children than children of control group A, and the total proportion of nephrotic children with any positive test $(52 \%)$ was significantly higher than the proportion of controls with a positive test $(26 \%)$ (Table 3).

No late skin reactions of the type III hypersensitivity response were observed or reported in any child.

Fig. 3 shows the allergens that most often produced a positive response in the nephrotic children compared with the allergens that most often produced a
Table 3 Frequency of positive skin prick tests

\begin{tabular}{|c|c|c|c|c|c|}
\hline \multirow[t]{2}{*}{ Grade } & \multicolumn{2}{|c|}{$\begin{array}{l}\text { Nephrotic syndrome } \\
(n=77)\end{array}$} & \multicolumn{2}{|c|}{$\begin{array}{l}\text { Controls } \\
(n=50)\end{array}$} & \\
\hline & No & $\%$ & $N o$ & $\%$ & \\
\hline $\begin{array}{l}\text { A } \\
\text { B } \\
\text { C } \\
\text { Total A B C } \\
\text { Negative }\end{array}$ & $\begin{array}{l}14 \\
12 \\
14 \\
40 \\
37\end{array}$ & $\begin{array}{l}18 \\
16 \\
18 \\
52 \\
48\end{array}$ & $\begin{array}{r}5 \\
4 \\
4 \\
13 \\
37\end{array}$ & $\begin{array}{r}10 \\
8 \\
8 \\
26 \\
74\end{array}$ & $(P<0.01)$ \\
\hline
\end{tabular}

\section{Incidence of positive skin tests} (Weal diameter $\$ 2 \mathrm{~mm}$ )
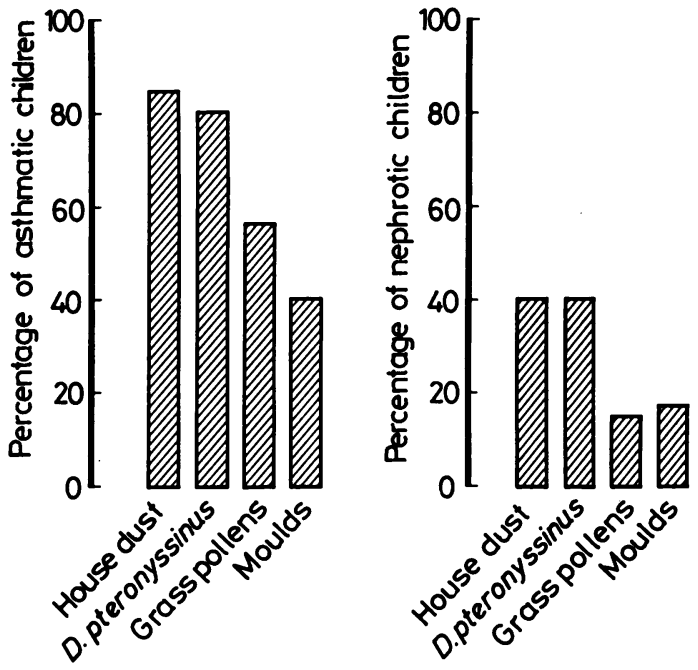

Fig. 3 Incidence of positive skin prick tests to common allergens in children with nephrotic syndrome compared with children with asthma.

positive response in 133 asthmatic children in the Leeds area. The pattern was similar in both groups but far more children with asthma had positive responses to skin tests.

\section{Blood eosinophil count}

It is usual to consider levels above $0.4 \times 10^{9} / 1$ as abnormal. Thirteen $(21 \%)$ of 62 nephrotic children had peripheral blood eosinophil counts of $>0.4$ $\times 10^{9} / 1$. Two $(7 \%)$ of 30 control children from group A had similar eosinophilia.

\section{Management trials}

Three separate trials were carried out on (1) allergen avoidance, (2) disodium cromoglycate, (3) BRL 10833. 
The procedure used for testing urine samples and identifying relapse was similar in each of these trials. Second morning urine specimens were tested daily using chemically impregnated plastic test strips (Albustix by Ames Company). The results were recorded daily on a recording form. If 3 consecutive daily specimens showed an Albustix reading of $2+$ or more, a timed collection of urine was made for accurate quantitative determination. Relapse was defined as a protein excretion of $>50 \mathrm{mg} / \mathrm{kg}$ per day.

Allergen avoidance. Any child who had at least one positive radioallergosorbent test for specific IgE to a food, or a pet, was told to avoid that particular food or animal; there were 8 such children. At the time of the trial 5 children (group C) were dependent on corticosteroids in order to stay in remission. The other 3 children (group D) had required at least 2 courses of corticosteroids during the previous year because of relapse of nephrotic syndrome. All were in remission. A special diet was constructed which was not only free of suspected allergens but was also low in other foods that have a reputation for causing allergic symptoms in the UK. The diet was begun in hospital and the parents were instructed in its preparation and use before the child was allowed home.

For a child suspected of being allergic to an animal extensive discussion took place with the parents in order to reduce to a minimum the chance of the child coming into contact with the animal either directly or indirectly.

This avoidance regimen was begun in hospital, and once it was fully understood and was likely to be complied with satisfactorily, the child was allowed home to continue with the same regimen. The prednisolone was continued in the initial dose for the first 2 weeks and then was gradually reduced until at 4 weeks it was stopped.

\section{Results}

All 5 children in group $C$ relapsed within 4 weeks of stopping prednisolone. All the parents stated that the allergen avoidance regimen had been maintained.

The children in group D persisted with allergen avoidance for 6 months but this still did not prevent relapse of nephrotic syndrome and did not appear to make any appreciable difference to the frequency of relapse.

Disodium cromoglycate. Ten children with frequently relapsing nephrotic syndrome were receiving regular treatment with corticosteroids (mean dose 29 $\mathrm{mg} / \mathrm{m}^{2}$ every other day) at the time the trial began.
Each was placed in a treatment group or a control group, ensuring that the children in each were of comparable age and taking a comparable prednisolone dose, and that atopic features (incidence of symptoms, positive skin prick test, and raised $\operatorname{IgE}$ levels) were also similar.

The treatment group received disodium cromoglycate in each of the following three forms for 42 days: (1) $20 \mathrm{mg}$ spincap (Intal plain) inhaled from spinhaler twice daily. (2) $20 \mathrm{mg}$ spincap (Intal plain) contents ingested orally twice daily. (3) $10 \mathrm{mg}$ insufflation capsule (Rynacrom) taken as 2 sprays to each nostril 3 times daily.

Doses of prednisolone began to be reduced 2 days after starting disodium cromoglycate, and continued to be so until all corticosteroids had been stopped at 28 days. Prednisolone was reduced and then stopped in a similar manner for children in the control group.

\section{Results}

All the children relapsed within 11 weeks of stopping prednisolone. Three of the 5 children who were having disodium cromoglycate relapsed while still receiving the drug. The other 2 relapsed, 1 of them one week after, and the other 7 weeks after stopping disodium cromoglycate. The treatment group had a combined total of 33 weeks in remission, whereas the control group had 40 weeks in remission.

BRL 10833. This drug is a new nitroindanedione derivative and has antiallergic activity when taken orally. Treatment with BRL 10833 did not prevent relapse in 6 children with steroid-dependent nephrotic syndrome who had required $>10 \mathrm{mg} / \mathrm{m}^{2}$ alternateday prednisolone. For 4 children who had required $<10 \mathrm{mg} / \mathrm{m}^{2}$ alternate-day prednisolone the 56 days of BRL 10833 may have prevented relapse during treatment but it did not induce a long remission. Further details of this trial have been described. ${ }^{6}$

\section{Discussion}

This enquiry into atopic disorders in the nephrotic children and their relatives was confined to asthma, eczema, allergic rhinitis, and recurrent urticaria. Some studies have been carried out on at least 50 symptoms-such as sweating, erratic appetite, flatus, and urgency of micturition. ${ }^{7}$ The limited and clearly-defined atopic disorders sought by us proved to be easily identifiable in the children and in the 1st-degree relatives. Moreover our method minimised observer bias.

There was a significant increase of atopic disorder in the nephrotic children compared with the hospital control group A. The difference is even more 
pronounced if the nephrotic children are compared with the healthy schoolchildren (control group B). The $13 \%$ incidence of atopic disease in control group B is close to the incidence of $15 \%$ found in a large Swedish survey ${ }^{8}$ and comes within the $12-20 \%$ range which is often quoted as being the incidence of atopic disease in Europe and North America. ${ }^{9}$ The 1st-degree relatives of the nephrotic children also had an appreciably higher incidence of atopic disorders than the healthy controls. This was expected in view of the likely genetic influences on atopic disease and its expression.

An increased incidence of atopic disease in children with nephrotic syndrome has been suggested by the work of Ohnishi in Japan ${ }^{10}$ and Thomson et al. in London. ${ }^{11}$ Our survey which was larger, more detailed, and used stricter diagnostic criteria confirms that there is an increased incidence.

Despite the fact that 26 nephrotic children gave a clear history of atopic disorders, only 5 of them had had an episode of that disorder immediately before, or at the time of onset of nephrotic syndrome. None of them could produce a convincing history of an association between atopic symptoms and nephrotic syndrome; the exacerbations of, for instance, asthma were unrelated in time to the relapses of nephrotic syndrome.

An important symptom volunteered by parents of half the nephrotic children was that onset of the syndrome or relapse was often linked with 'a cold' or 'a runny nose'. In a few cases this was clearly a viral infection affecting others in the family, but for many children the parents maintained 'it was not a cold, just a runny nose'. If such cases had been included as examples of allergic rhinitis (which they may be), the incidence of atopy in the nephrotic children would have been very high. The difficulty was that despite careful questioning no provocative factor could be found to account for the runny nose. It is interesting that a runny nose was not common in the 12 children who each had only had a single bout of nephrotic syndrome.

Seasonal factors were not found to be important in relation to the onset of nephrotic syndrome or to subsequent relapses. In our region the pollen season is mainly in May, June, and July, whereas house-dust mite, another common allergen, is more prevalent in September and October. There was nothing in the timing of the nephrotic syndrome to suggest a common relationship to these seasons. In view of the well-documented cases of nephrotic syndrome associated with hay fever it was notable that only 4 out of 77 children had a history of hay fever and that only one had had a relapse at the time of allergic rhinitis in the pollen season. Seasonal nephrotic syndrome does occur ${ }^{4}$ but this survey suggests that it is a rare accompaniment of troublesome nephrotic syndrome, since the nephrotic children in this survey represent the more difficult cases from a catchment area of 5 million population during a 6-year period.

The absence of a consistent relationship between month of birth, month of onset of nephrotic syndrome, and the pattern of the illness did not support the type of sensitisation phenomenon which may be relevant to the acquisition of sensitivity in early life for children with asthma and eczema. ${ }^{12-14}$

Nearly half $(40 \%)$ of the nephrotic children had at least one positive skin response. This was significantly greater than the control group. It is also higher than the $20 \%$ which is quoted as being the maximum frequency of abnormal skin tests in healthy 'non-allergic' people. ${ }^{15}$

The increase in positive skin tests fits in with the earlier finding of an increased incidence of atopic disorder in nephrotic children. An increased incidence of positive skin tests to grass pollen compared with controls was found in nephrotic children by Thomson and colleagues. ${ }^{11}$ Although each child was tested with at least 8 different allergens, positive responses were mainly confined to house-dust, house-dust mite, grass pollens, and moulds. This was similar to the findings on asthmatic children in the Leeds area.

The results of the management trials were disappointing. For allergen avoidance to be successful one needs to be sure that one particular allergen alone is responsible for the symptoms and that it is possible to avoid it. Allergen avoidance was unsuccessful in the 8 children on whom it was inflicted. The evidence that an allergen might be responsible came partly from the history and partly from the fact that each child had a positive response to the radioallergosorbent test for that particular allergen. But in no case was the history as convincing as one would have liked, and the results confirmed that avoiding the suspected allergen did not help in the short term.

During the preparation for this trial it became clear how extremely difficult it is to define the allergens in various environments. Although parents suggested factors-such as the water at Scarborough, the school hamster, or a change in the weather-as preceding each relapse, further questioning led to many other variable factors. One Asian child who relapses regularly in Yorkshire had spent two long periods with relatives in Pakistan where she is relapse-free and no longer needs corticosteroids to stay in remission. It seems logical to implicate adverse environmental factors in Yorkshire (or 
protective ones in Pakistan), but the list is very long; different foods, water, climate, clothing, housing, micro-organisms, etc. So far we have failed to identify which factor, or combination of factors, causes her to be healthy in Pakistan and ill in Yorkshire.

There has been a report of diminished proteinuria in 6 American children who were put on an 'elemental fluid diet' ${ }^{16}$ It was claimed that milk hypersensitivity was the cause of the nephrotic syndrome. However, to be certain that a food is responsible for an intermittent disorder there must be remission when the child stops eating it, relapse when it is reintroduced, and continued remission with continued avoidance.

Disodium cromoglycate was tried because of its proved efficacy for extrinsic asthma. At the time of the trial its efficacy by powder inhalation for asthma and by nasal insufflation for hay fever had been established ${ }^{17}$ and there were preliminary reports that oral cromoglycate might be effective for various gastrointestinal disorders. ${ }^{18}$ We decided to give it by three different routes because of the possibility that it might be effective either because of its activity at mucus membranes, or by virtue of the $4 \%$ of it that is absorbed after inhalation, or even by virtue of the proportion of the absorbed drug that is excreted in the urine. ${ }^{19}$

Disodium cromoglycate did not appear to prevent or delay relapse in the children to whom it was given. All relapsed during or shortly after they had stopped taking prednisolone. Concurrently a similar trial of cromoglycate was taking place in London. ${ }^{20}$ That trial too failed to demonstrate benefit to the children receiving the drug, although one child had previously been encountered with hay fever and summertime relapses of nephrotic syndrome who might have been helped by intranasal cromoglycate.

The pattern of absorption and excretion of disodium cromoglycate means that it has little chance of systemic effect, apart from that resulting from its activity at surfaces - nasal, pulmonary, and alimentary mucus membranes. It had been hoped that if a drug of similar action and which, too, was absorbed could be developed, further benefit might be achieved. This is an arguable hypothesis, since cromoglycate itself acts on mast cells which are particularly numerous in those areas to which current forms of cromoglycate administration deliver it. However, there was the possibility that an orally absorbed drug which stablised mast cells might be beneficial to some children with nephrotic syndrome. Our carefully controlled trial of BRL 10833 did not benefit many of the nephrotic children. It is possible that it was helpful to a few children who had formerly taken low doses of maintenance prednisolone, but such children do not present difficult clinical problems and few would be considered suitable for the drug. A trial of another new mast cell stabilising drug doxantrazole has been disappointing too. ${ }^{21}$

Pollen hypersensitivity is a rare cause of nephrotic syndrome. It is logical to expect other allergens to cause nephrotic syndrome, particularly as we have shown such children to have an increased incidence of atopy. However, our own work, and that of others, suggests that at present various antiallergic manoeuvres fail to help children with steroidresponsive nephrotic syndrome. This may be because hypersensitivity plays no causal role. It equally well could result from our failure to identify the provoking allergen.

We thank the paediatricians who referred the children, the staff in Leeds who helped in their care and investigation, the Medical Illustration Department, St James's University Hospital, our assistant Mrs Wendy Pearson, Dr G Wainscott and Dr J T Brocklebank who assisted with the BRL 10833 treatment trial, and Beecham Research Laboratories for supplying the trial drug.

The Children's Kidney Fund, University of Leeds, provided financial support.

\section{References}

1 Hardwicke J, Soothill J F, Squire J R, Holti G. Nephrotic syndrome with pollen hypersensitivity. Lancet 1959; i: 500-2.

2 Wittig H J, Goldman A S. Nephrotic syndrome associated with inhaled allergens. Lancet 1970 ; i: 542-3.

3 Williamson D A J. Letter: Nephrotic syndrome associated with inhaled allergens. Lancet 1970; i: 778.

4 Reeves W G, Cameron J S, Johansson S G O, Ogg C S, Peters D K, Weller R O. Seasonal nephrotic syndrome. Clin Allergy 1975; 5: 121-37.

5 Squire J R. The relationship between horse dandruff and horse serum antigens in asthma. Clin Sci 1950; 9: 127-50.

6 Meadow S R, Brocklebank J T, Wainscott G. Letter: Anti-allergic drugs in idiopathic nephrotic syndrome of childhood. Lancet 1978; i: 1200.

7 Fontana V J, Spain W C, Desanctis A G. The role of allergy in nephrosis. NY State J Med 1956; 56: 3907-10.

8 Kjellman N I M. Atopic disease in seven-year-old children. Acta Paediatr Scand 1977; 66: 465-71.

- Rapaport H G, Appel S J, Szanton V L. Incidence of allergy in a pediatric population. Ann Allergy 1960; 18: 45-9.

10 Ohnishi M, Kimura K, Matsumoto T, Sakamoto F, Yamaguchi M, Kadowaki J. Idiopathic nephrotic syndrome and atopic features. In the proceedings of the Fourteenth Annual Meeting of the Japanese Society of Paediatric Nephrology 1978. Abstract 97. 


\section{Meadow and Sarsfield}

11 Thomson P D, Stokes C R, Barratt T M, Turner M W, Soothill J F. HLA antigens and atopic features in steroidresponsive nephrotic syndrome of childhood. Lancet 1976; ii: $765-8$.

12 Taylor B, Norman A P, Orgel H A, Stokes C R, Turner M W, Soothill J F. Transient IgA deficiency and pathogenesis of infantile atopy. Lancet 1973; ii: 111-3.

13 Soothill J F, Stokes C R, Turner M W, Norman A P, Taylor B. Predisposing factors and the development of reaginic allergy in infancy. Clin Allergy 1976; 6: 305-19.

14 Warner J O, Price J F. House dust mite sensitivity in childhood asthma. Arch Dis Child 1978; 53: 710-3.

15 Hagy G W, Settipane G A. The frequency of allergens and positive skin tests among college students (abstract). $J$ Allergy 1966; 37: 107-8.

16 Sandberg D H, McIntosh R M, Bernstein C W, Carr R, Strauss J. Severe steroid-responsive nephrosis associated with hypersensitivity. Lancet 1977 ; i: 388-91.

17 Bierman C W, Soyka L F. The use of cromolyn sodium in the treatment of asthma in children. Pediatrics 1975; 55: $586-8$.

18 Freier S, Berger H. Disodium cromoglycate in gastrointestinal protein intolerance. Lancet 1973; i: 913-5.

19 Walker S R, Richards A J, Paterson J W. The absorption, excretion, and metabolism of disodium $\left({ }^{14} \mathrm{C}\right)$ cromoglycate in man (abstract). Biochem J 1971; 125: 27P.

20 Trompeter R S, Thomson P D, Barratt T M, Soothill J F. Controlled trial of disodium cromoglycate in prevention of relapse of steroid responsive nephrotic syndrome of childhood. Arch Dis Child 1978; 53: 430-2.

21 Bluett N H, Chantler C, Hughes D T. Letter: Failure of doxantrazole in steroid-sensitive nephrotic syndrome. Lancet 1977; i: 809.

Correspondence to Professor S R Meadow, Department of Paediatrics and Child Health, St James's University Hospital, Beckett Street, Leeds LS9 7TF.

Received 25 May 1980 